\title{
A SURFACE ALBEDO PRODUCT AT HIGH SPATIAL RESOLUTION FROM A COMBINATION OF SENTINEL-2 AND LANDSAT-8 DATA: THE ROLE OF SURFACE RADIATIVE FORCING FROM AGRICULTURE AREAS AS A MAJOR CONTRIBUTOR TO AN ABATEMENT OF CARBON EMISSION
}

\author{
J.-L. Roujean ${ }^{1 *}$, A. Olioso ${ }^{2}$, E. Ceschia ${ }^{1}$, O. Hagolle ${ }^{1}$, M. Weiss ${ }^{2}$, T. Tallec ${ }^{1}$, A. Brut ${ }^{1}$, and M. Ferlicoq ${ }^{1}$ \\ ${ }^{1 *}$ CESBIO UMR 5126, 18 avenue E. Belin, bpi 2801, 31055 Toulouse Cedex 09, France - jean-louis.roujean@cesbio.cnes.fr \\ ${ }^{2}$ UMR 1114 EMMAH, INRA Domaine St Paul, 84914 Avignon, France
}

Commission III, WG III/10

KEY WORDS: Sentinel-2, albedo, agriculture, carbon.

\begin{abstract}
:
Satellite Sentinel-2 offers a global coverage of the Earth surface at the frequency of a few days with pixel size ranging from 10 to 60 meters. Such spatio-temporal resolution fosters an advanced research in agricultural area notably. The role of the surface albedo as a mean to reduce the surface radiative forcing in link to agriculture practice is a real concern. A high resolution (HR) surface albedo is now generated routinely from the observations of satellites Sentinel-2A \& -2B for the time being plus Landsat in the near future. The methodology inherited from the Global Land Service of Copernicus is presented with some preliminary results.
\end{abstract}

\section{INTRODUCTION}

The advent of fleet such like the satellites Sentinel-2A and -2B permits the Earth observation research to enter into a new era owing to a frequent revisit of the globe at appropriate time and spatial resolution. Besides, the level of quality of the data processed from lessons learned promotes an operational use of HR (High Resolution) information, notably in the frame of the European Commission's Copernicus program [1]. This is to answer favourably to an increasing demand for accurate and reliable environmental data. In particular, it aims at providing a permanent monitoring of the land territories. The spectral characteristics of Sentinel-2 sensor allow measuring the biophysical variables describing the vegetation conditions, the energy budget and the water cycle over the entire globe. These generic products can serve numerous applications such as agriculture and food security, weather forecast, climate change impact studies, water, forest and natural resources management. To be outlined that the Sentinel-2 mission expands on the French SPOT and US Landsat missions. Particularly, the footprint of 30 meters from Landsat- 8 is compliant with the 10 and 20 meters pixel resolution of Sentinel-2, in order to strengthen both spatial and temporal coverage. A merged reflectance product in a spectral domain covering visible, near infrared and mid-infrared offers new challenge for collecting cutting-edge information about the monitoring of crops. The outcomes of the dissemination of quality-checked HR product will certainly benefit to programs like GEOGLAM (Group of Earth Observation for Global Agricultural Monitoring) for which main concerns are the onset and decay of crops, and early warning. The presentation will highlight the operational methodology to be implemented in order to perform a measurement of the HR surface albedo and also ensure a trimmed monitoring of the worldwide crops.

\section{DEVELOPING A SURFACE ALBEDO PRODUCT AT HIGH RESOLUTION}

The surface albedo is an Essential Climate Variable (ECV) that needs to be generated on a regular basis in order to ensure continuous estimates as a contribution of the radiation budget to water and carbon balance. Amongst key issues are a timely production, the availability of historical archives, and the consistency of time series as long as possible. First of all, the removal of atmospheric effects must be properly handled. Herein, inputs like water vapour content and ozone are issued from ECMWF (European Center for Medium Weather Forecast). Cloud removal and aerosol correction rely on the MAJA method proved to be efficient for processing multitemporal and multi-spectral data sets [2]. The present developments are intended to generate a time evolving HR surface albedo product with pixel size of 10 meters. A composite period of 60 days must be considered to gather sufficient observations in order to build a BRDF product. The surface albedo is refreshed during synthesis periods of 10 days. Due to the scarcity of clear scenes, a few parameters are to be retrieved to make the product. Hence, the method - to be operational - makes use of the well-established approach based on a semi-empirical BRDF kernel-driven [3]. The BRDF model is applied to Level 2A of selected Sentinel-2 bands as displayed in Figure 1. Broadband albedo products were derived using narrow to broadband conversion coefficients based on numerical experiments using the PROSAIL radiation transfer model. BRDF coefficients can also serve to perform a normalization of the data. In order to best answer users requirements, the surface albedo products are delivered with a Quality Flag and an uncertainty assessment. Also the true age of the product is indicated as being the median value of the clear sky scenes used. The methodology displayed in Figure 1 is similar to a methodology recently developed for PROBA-V sensor to obtain a 300 meters surface albedo product in the frame of the Copernicus Global Land Service [4]. 


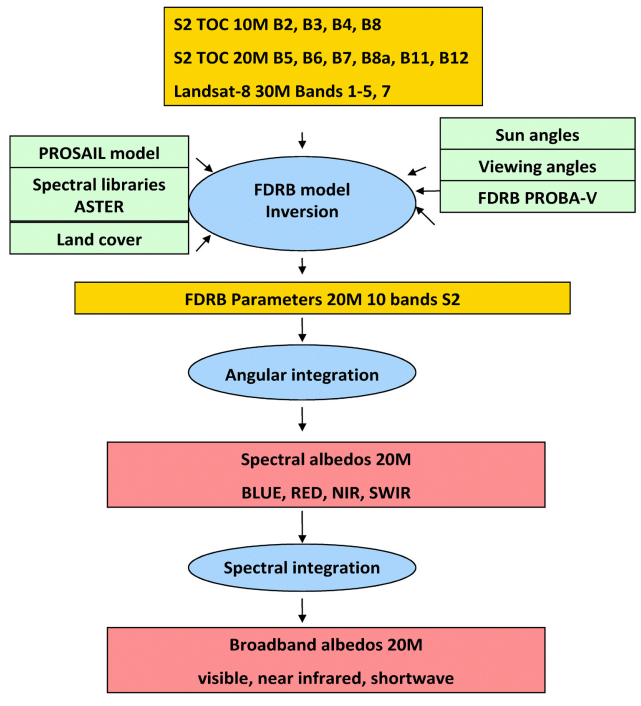

Figure 1: Flow chart of the algorithm for BRDF model inversion and albedo determination.

Time series for 2018 of Directional-Hemispherical (AL-BB$\mathrm{DH})$ and Bidirectional-Hemispherical (AL-BB-BH) shortwave albedo products at 10 meters resolution are shown in Figure 2. It is also shown Sentinel-2 Level 2A data sets produced by MAJA processing chain at CNES. Also reported are ground data from the two ICOS stations of Auradé and Lamasquère located near Toulouse and maintained by CESBIO. These sites are covered by crops (maize, wheat, and sunflower, merely) overhung by albedometers mounted on a tower flux. Two comparable INRA stations close to the Mediterranean coast are also considered for validation. The cross-evaluation between satellite and in situ albedo products looks at the rendered seasonality. The HR sensor footprint also permits a comparison with the signal intensity. It follows that error analysis will help pointing out the possible role of BRDF sampling and aerosol on the accuracy assessment of spectral surface albedo.
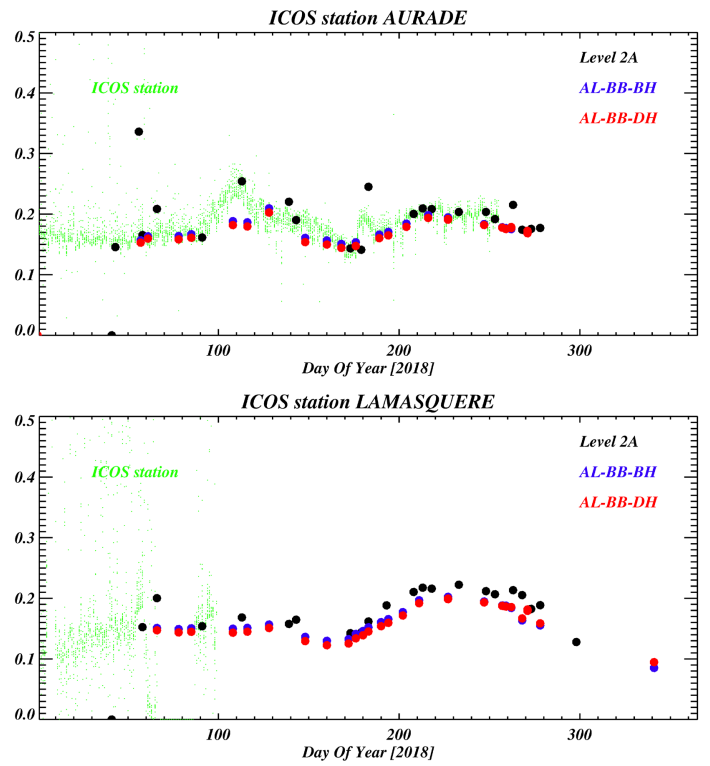

Figure 2: Time series of HR surface albedo products over the ICOS stations of CESBIO.
Another method based on the training of a Neural Network $(\mathrm{NN})$ from PROSAIL simulations is also considered. The method was proven successful to obtain surface albedo product from HR sensor FORMOSAT [5]. Such approach is powerful to compute the surface albedo from a limited data set but shows limits to perform the extrapolation of the data information, depending on the sampling quality. NN will serve to establish relationships between the surface albedo estimated from BRDF kernel-driven model and limited angular sampling and the true surface abedo. In both approach, a consolidated method for normalizing and merging data is be considered and applied [6].

Hitherto, a continuous validation of the surface albedo product based on the NN approach is performed by INRA over various ecosystems of the area Avignon-Crau-Camargue for the case of reference of MODIS and PROBA-V. It is based on four groundbased measurements. Recently, procedure for a systematic accurate assessment of surface albedo products was developed and implemented for both high and moderate spatial resolution sensors [7] [8]. Some tests to be considered preliminary consisted to calculate the surface albedo from Sentinel 2A for the period 2016-2017. It was a simple linear combination of the spectral reflectance value corrected from atmospheric effects. It comes out that a surface albedo product calculated such a way is particularly sensitive to the geometry of acquisition of the Sentinel-2 pixel. This feature was observed whereas 10-days routine acquisitions were obtained from two different Sentinel-2 orbits taken away in the time of three days with one scanning eastward and the other one westward (zenith angle close to $8^{\circ}$ for the two orbits and azimuth angle of $106^{\circ}$ and $286^{\circ}$, respectively). The two orbits provide albedo values to be significantly different on a systematic basis (pixel difference between 0.01 and 0.05 in absolute albedo unit). Such deviations explain in part by the use of similar linear combinations for the different viewing directions. To be outlined that atmospheric correction could also have an impact. However, simulation of surface albedo from NN using now narrow to broad-band linear relationships for different viewing geometry of Sentinel-2 improved the results in regard to the temporal coherence and retrieved precision (see Figure 3).
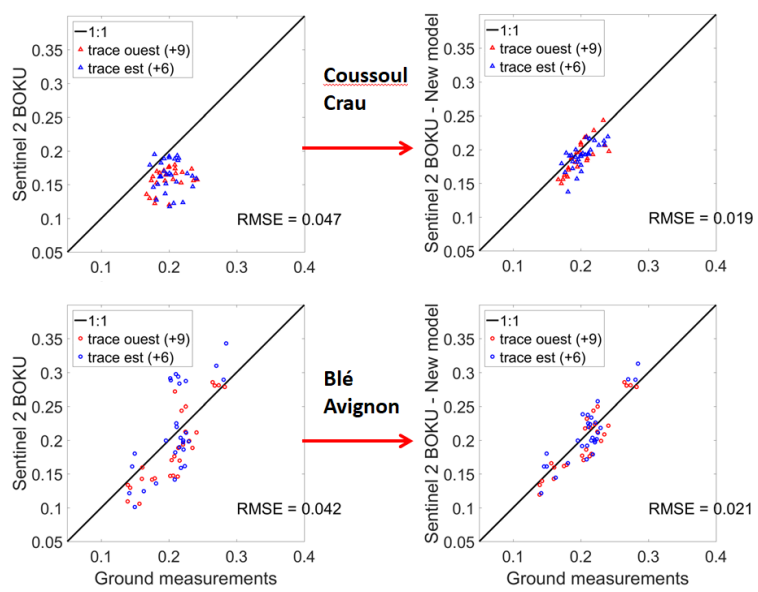

Figure 3 : Comparison of estimated albedo by comparison with ground-based measurement over two sites located at $\mathrm{La}$ Crau and in Avignon. Left hand: a unique linear combination. Right hand: a different linear combination for each geometry of measure. 


\section{SUMMARY AND FUTURE PROSPECTS}

An initiative is undertaken to provide operational global estimates of the surface albedo fields (spectral and broadband). It is based on a combination of Sentinel-2A \& $-2 B$ and Landsat observations to finally deliver products at spatial resolution of 10 meters. This will clearly offer a great potential in agricultural area. Owing to a high spatial resolution, and despite the lack of thermal bands for Sentinel-2, it is glimpsed that surface albedo product quality would benefit of reliable cloud detection due to the high pixel resolution that allows discarding notably low broken clouds. Besides, the analysis will be implemented to map distinctly snow-free and snow pixels with different strategies of temporal sampling, and also bare soil and vegetation pure albedo products.

The ongoing validation is based on a cross-comparison with ground networks like ICOS stations maintained by CESBIO in south-west of France. Also, it is foreseen to degrade the high resolution albedo until a spatial resolution that will permit a fair comparison with consolidated surface albedo products issued from MODIS and also PROBA-V in the frame of the Global Land Service of Copernicus. To be outlined that the narrow to broadband conversion - based on numerical experiments from PROSAIL - represents an important step. The production of dynamic maps of the spectral surface albedo from Sentinel-2 bands, further converted into broadband in support to water and carbon studies, is foreseen. The product spatial resolution of 10 meters is fully compliant with crops in terms of description and validation. Therefore, the product should offer new insights to our knowledge of agriculture at broad scale.

\section{ACKNOWLEDGMENTS}

The authors feel indebted to the French Space Agency CNES and TOSCA committee for supporting this work.

\section{REFERENCES}

[1] Copernicus Global Land service:
http://land.copernicus.eu/global/

[2] Hagolle, O., M. Huc, D. Villa Pascual and G. Dedieu, A Multi-Temporal and Multi-Spectral Method to Estimate Aerosol Optical Thickness over Land, for the Atmospheric Correction of FormoSat-2, LandSat, VEN $\mu \mathrm{S}$ and Sentinel-2 Images, Remote Sensing of Environment, 2015, 7, pp. 26682691; doi: 10.3390/rs 70302668.

[3] Roujean, J.L., M. Leroy, and P.Y. Deschamps, 1992. A bidirectional reflectance model of the earth's surface for the correction of remote sensing data. Journal of Geophysical Research, pp. 97, 20,455-20,468.

[4] Roujean, J.L., J. Leon-Tavares, B. Smets, P. Claes, F. Camacho de Coca, and J. Sanchez-Zapero, Surface albedo and TOC-R $300 \mathrm{~m}$ products from PROBA-V instrument in the framework of Copernicus Global land Service, Remote Sensing of Environment, in press.

[5] Bsaibes, A., Courault, D., Baret, F., Weiss, M., Olioso, A., Jacob, F., Hagolle, O., Marloie, O., Bertrand, N., Desfond, and V., Kzemipour, F., 2008. Albedo and LAI estimates from FORMOSAT-2 data for crop monitoring. Remote Sensing of Environment.pp. 113, 716-729.

[6] Samain, O, B. Geiger, and J.-L. Roujean, Spectral normalization and fusion of optical sensors for the retrieval of
BRDF and albedo: Application to VEGETATION, MODIS and MERIS data sets, IEEE Transactions on Geoscience and Remote Sensing, Vol. 44, 11, Part 1, pp. 3166- 3179, 2006.

[7] Mira M., Weiss M., Baret F., Courault D., Hagolle O., Gallego-Elvira B., Olioso A., 2015. The MODIS (collection V006) BRDF/albedo product MCD43D: temporal course evaluated over agricultural landscape. Remote Sensing of Environment, pp. 170, 216-228.

[8] Mira M., Olioso A., Gallego-Elvira B., Courault D., Garrigues S., Marloie O., Hagolle O., Guillevic P., Boulet G., 2016. Uncertainty assessment of surface net radiation derived from Landsat images, Remote sensing of Environment, pp. 175, 251-270. 